\title{
An innovative system for online evaluation of denitration catalyst activity and automatic adjustment of AIG spray distribution
}

\author{
Ruifeng Dong1,a, Yang Guo ${ }^{1,2, b}$ and Xueying Zhang ${ }^{1, c}$ \\ ${ }^{1}$ State Grid Henan Electric Power Research Institute, Zhengzhou 450052, China \\ 2 Henan EPRI Hitech Group Co., Ltd., Zhengzhou 450052, China \\ adrfcom2005@163.com, b guoyanghh@126.com, chnzhangxueying@163.com
}

\begin{abstract}
Keywords: Online Evaluation; Denitration Catalyst Activity; Automatic Adjustment; AIG Spray Distribution

Abstract. In order to detect the performance of SCR denitration catalyst activity online, and optimize the AIG spray distribution automatically, an innovative system is proposed. The system could monitor the $\mathrm{NO}_{x}$ concentration distributions of SCR inlet and outlet flues simultaneously. According to the distributions of $\mathrm{NO}_{x}$ concentration and flue gas flow rate, the performance of SCR denitration catalyst could be detected. After the analysis of parameters, DCS could adjust the automatic regulating valve to optimize the AIG spray distribution. An optimal $\mathrm{NO}_{x}$ concentration distribution of SCR outlet flue will be realized, which lead to the minimal $\mathrm{NH}_{3}$ consumption and escape concentration. With the proposed system, the working condition of SCR system could be optimized automatically. Better economic and environmental indicators can be received for coal-fired power plants.
\end{abstract}

\section{Introduction}

Coal-fired power plants are the main electric power sources of China [1]. Along with the worse environmental condition, the flue gas purification is getting more important. $\mathrm{NO}_{x}$ is one of the most common contaminants in coal-fired power plants [2]. There are many processes for flue gas denitration, such as selective catalytic reduction (SCR), selective non-catalytic reduction (SNCR), et al. SCR denitration is the most mature and widely used technology in coal-fired power plants [3]. However, there are also many problems during the operation process [4]. The catalyst activity and ammonia escape are two main problems for SCR system. The reduction of catalyst activity could lead to excessive emission of $\mathrm{NO}_{x}$, while ammonia escape could lead to equipment clogging problems.

The expected life expectancy of SCR denitration catalyst is normally three years. As time flows, the catalyst activity is reducing gradually. When the catalyst activity could not meet the demand, the $\mathrm{NO}_{x}$ concentration of the outflow flue gas will be above the emission standard. Under normal conditions, the catalyst activity will be measured in the denitrification test, which will be carried out once a year. What's more, the denitrification test could only reveal the overall denitrification performance. The catalyst activity distribution could not be tested. Therefore, a real-time online detection system for catalyst activity distribution is necessary for coal-fired power plants.

Ammonia is the most widely used reducing agent in SCR system. However, ammonia escape is a common and serious problem in the outlet flue gas. Escaped ammonia could be easily turned into ammonium bisulfate, because of the existence of sulphur trioxide in the flue gas. Ammonium bisulfate is the main reason of clogging and agglomeration problems in the air preheater and dust filter. In order to reduce the amount of escaped ammonia and improve the uniform distribution level of SCR outlet $\mathrm{NO}_{x}$ concentration, ammonia injection grid (AIG) adjustment and optimization is carried out once a year in coal-fired power plants. However, the distribution of SCR outlet $\mathrm{NO}_{x}$ concentration could be easily changed when the power generation load, the opening of the flue baffle or the flue gas velocity distribution changes. Therefore, it is necessary for coal-fired power plants to install a real-time online AIG adjustment system [5].

At present, all the AIG adjustment and optimization are carried out manually. The frequency of adjustment is about once a year. The automatic AIG adjustment is only a state-of-art technology. Qingchuan Zhao [6] proposed a flue gas distribution measuring device of SCR denitration system. 
The flue gas distribution measuring device can be used for completing flue gas component measurement of 60-100 grid points within 30 minutes to obtain $\mathrm{NO}_{x}$ distribution fields in the SCR denitration device. However, the distribution of flue gas velocity can not be obtained. The final balance of AIG could only be achieved after several rounds of measurement and adjustment, which is a waste of time. Dekui Shen [7] invented a SCR denitration system ammonia spraying optimization method based on weight valve regulation and control. The method is divided into four steps: measurement of flue gas flow field characteristics, analysis of flue gas flow field regional flow characteristics, determination of ammonia spraying weight valves and pertinence adjustment of opening degrees of the ammonia spraying valves. The method comprises the particular steps: firstly, measuring the flue gas flow field characteristics of a flue transverse section in front of an ammonia spraying grille of an SCR denitration system under a condition of constant load; then combining with a distribution condition of spray nozzles of the ammonia spraying grille, and analyzing flue gas flow field regional flow continuous distribution characteristics matched with the ammonia spraying spay nozzle distribution; according to the flue gas flow field regional flow characteristics under various load conditions, obtaining the weights of the ammonia spraying valves; and finally, adjusting the opening degrees of all the valves according to the valve weight difference, simultaneously, with the help of a flue gas analyzer, measuring the NOx outlet concentration on an outlet section of the SCR denitration system, and timely feeding back the adjustment effect of the opening degrees of the ammonia spraying valves. However, the method is taken out manually.

Because of the similarity of basic parameters for the real-time online catalyst activity detection system and AIG adjustment system, an innovative system with the both functions is proposed. Based on the distributions of $\mathrm{NO}_{x}$ concentration and flue gas velocity, the catalyst activity evaluation and AIG adjustment could be done simultaneously. The proposed system has a high economy and environmental performance for coal-fired power plants.

\section{System structure}

The proposed system for catalyst activity evaluation and AIG adjustment simultaneously is shown in Fig. 1. All the devices are listed and introduced. The system could easily be installed on the ordinary SCR systems.

In Fig. 1, many ordinary systems, such as rectifier, soot blower and so on, are not shown and marked out. However, the ordinary systems are existed in the device. The position of each system is not the same with the real systems. The distance between each two systems will be redesigned.

In Fig. 1, the imported flue of SCR system is connected with the export flue of boiler economizer, while the export flue of SCR system is connected with the imported flue of air preheater. Compared to the ordinary SCR system, a distributed matrix flowmeter, distributed flue gas sampling systems near the imported and export flues are added. The distributed matrix flowmeter can indicate the flowrate distribution of SCR imported flue. The distributed flue gas sampling system I and II can indicate the $\mathrm{NO}_{x}$ concentration distribution of SCR imported and export flues respectively. All the parameter values are transported to the distributed control system (DCS) for further analysis.

The distributed matrix flowmeter is different from the common matrix flowmeter. The common matrix flowmeter could only tell the average flowrate value of the flue cross section, while the distributed matrix flowmeter could reveal a series of flowrate value to get the flowrate distribution of the flue cross section. The devices are adjusted correspondingly.

The distributed flue gas sampling system I and II are the same in device structures. On the flue cross section, several flue gas sampling tubes are evenly distributed. All the flue gas sampling tubes are set in the support tube of flue gas sampling, as Fig. 2 shows. The sampling gases from flue gas sampling tubes are lead to the continuous emission monitoring system (CEMS) in the heat pipes, after the serial selection by switching device of sampling tubes and switching device of heat pipes. The switching devices are controlled by DCS. With the parameter value sequences transferred from 
CEMS, DCS could calculate and reveal the $\mathrm{NO}_{x}$ concentration distribution of SCR imported and export flues at the same time.

The measurement distance based on the grid method is limited by the site conditions, such as AIG distribution, the arrangement of monitoring holes and so on. All the parameters are fixed. The measurement time of one cycle is about half an hour. Therefore, the delay time of adjustment could be controlled under half an hour.

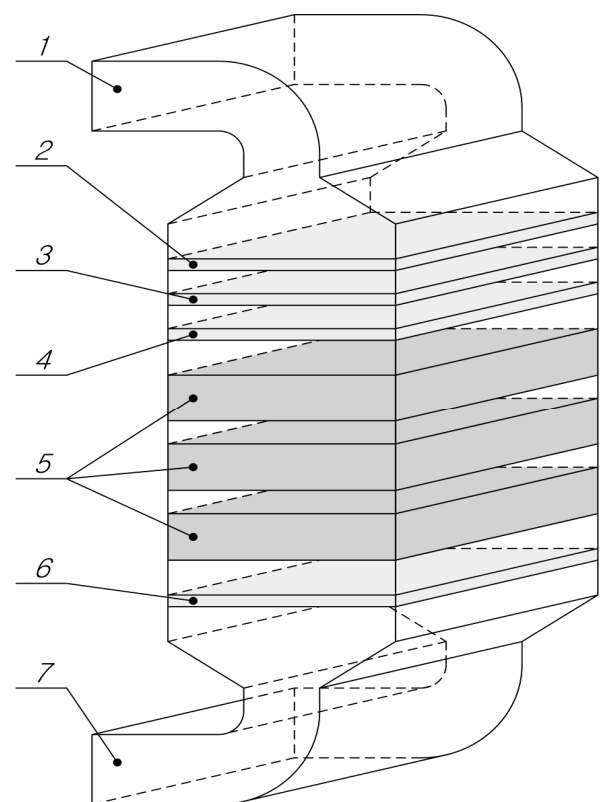

Figure 1. Illustration of system structure

1. Imported flue. 2. Distributed matrix flowmeter. 3. Distributed flue gas sampling system I. 4. AIG. 5. Catalyst layers. 6. Distributed flue gas sampling system II. 7. Export flue.

The AIG system will also be improved. All the manual regulating valves on spray ammonia tubes will be replaced by electric regulating valves. The opening of regulating valves will be controlled by DCS. The distribution of AIG ammonia spray flow can be adjusted automatically with the DCS signals. The illustration of AIG system is shown in Fig. 4. The flue gas sampling tube in Fig. 2 should be corresponded with the ammonia spray nozzle in Fig. 4 in spatial location. The illustration of switching device of sampling tubes is shown in Fig. 3.

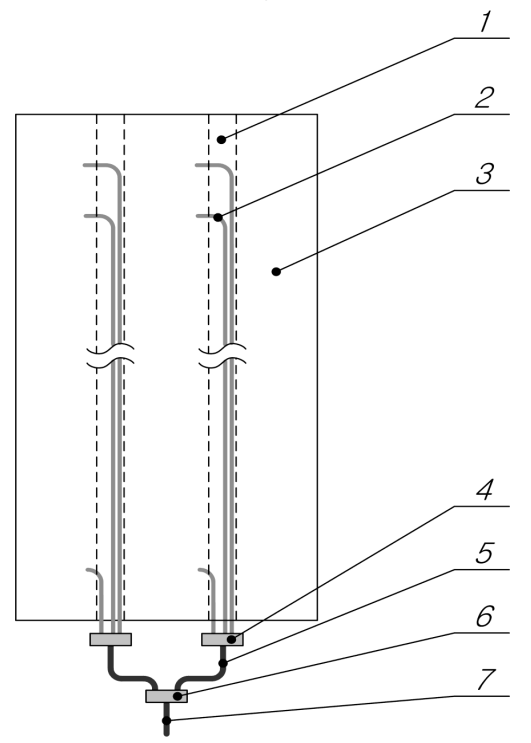

Figure 2. Illustration of distributed flue gas sampling system

1. Support tube of flue gas sampling. 2. Flue gas sampling tube. 3. Flue cross section. 4. Switching device of sampling tubes. 5. Heat pipe for flue gas sampling. 6. Switching device of heat pipes. 7. Heat pipe for CEMS flue gas sampling. 


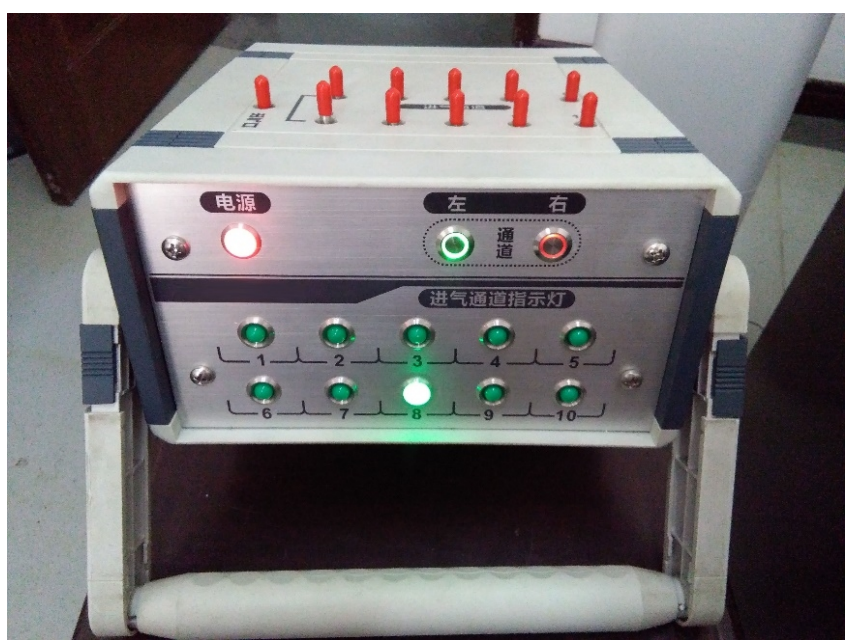

Figure 3. Illustration of switching device of sampling tubes

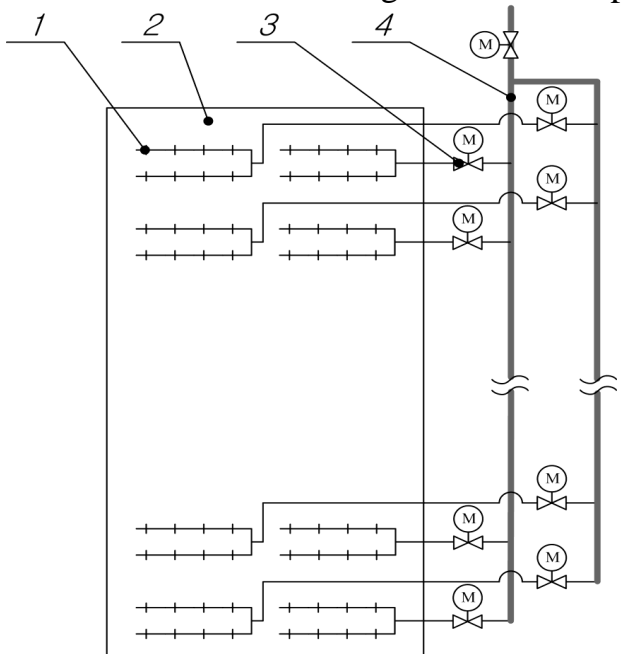

Figure 4. Illustration of AIG system

1. Ammonia spray nozzle. 2. AIG flue section. 3. Electric regulating valve. 4. Spray ammonia tube.

The catalyst layers are compose by $2-4$ SCR catalyst layers, which are the main places for denitrification reaction. The $\mathrm{NO}_{x}$ concentration will be reduced under emission standard and ultimately exhausted into the atmosphere.

\section{System functions}

With the proposed system, the catalyst activity evaluation and AIG adjustment could be carried out simultaneously.

Based on the online monitoring of distributions of flue gas velocity, inlet and outlet $\mathrm{NO}_{x}$ concentration, the distributions of catalyst activity could be evaluated. According to the historical data of catalyst activity, the lifecycle management of SCR catalyst could be carried out. The optimal replacement time of SCR catalyst can be obtained from DCS calculation. In the meantime, if any part of the SCR catalyst has the failure problem, the system could locate the area opportunely and precisely.

Based on the real-time monitoring of distributions of inlet and outlet $\mathrm{NO}_{x}$ concentration, DCS could calculate and adjust the AIG ammonia spay distribution at all times. The ammonia escape concentration could be controlled at minimum concentration. The clogging and agglomeration problems in the air preheater and dust filter can be solved eventually.

The distribution of flue gas velocity could easily be measured by each Pitot tube flowmeter placed in the 'Distributed matrix flowmeter' section. The distribution of inlet and outlet $\mathrm{NO}_{x}$ concentration could be measured by CEMS by switching and connecting to each flue gas sampling tube successively with the help of switching devices. All the data are measured and analyzed automatically. The opening degree of each AIG electric regulating valve is calculated and controlled by DCS. 
In summary, with the real-time online catalyst activity evaluation and AIG adjustment, the working performance of SCR system could be monitored and optimized at all times. The reliability of SCR system is enhanced hugely for coal-fired power plants.

\section{Experiment}

To verify the behavior of proposed system, an experiment is carried out in one coal-fired power station. The original SCR system is upgraded. The distributed matrix flowmeter and distributed flue gas sampling system are installed and connected to DCS and CEMS. The flue sizes of the inlet and outlet of SCR are all $15.5 \mathrm{~m} \times 3.5 \mathrm{~m}$. The flue gas temperature during the experiment is $340-350{ }^{\circ} \mathrm{C}$. The flue gas flowrate is $11-12 \mathrm{~m} / \mathrm{s}$.

The results of experiment are shown in Table 1. Before the running of system, the distribution of outlet $\mathrm{NO}_{x}$ concentration is obviously uneven. After adjustment by the system, the distribution of outlet $\mathrm{NO}_{x}$ concentration tends to be uniform. Even when the power generation load changes, the distribution of outlet $\mathrm{NO}_{x}$ concentration remains uniform at real time. The relative standard deviation (RSD) of the distribution of outlet $\mathrm{NO}_{x}$ concentration could be under $10 \%$ at all times.

Table 1. The distribution of outlet $\mathrm{NO}_{x}$ concentration (Unit: $\mathrm{mg} / \mathrm{m}^{3}$ )

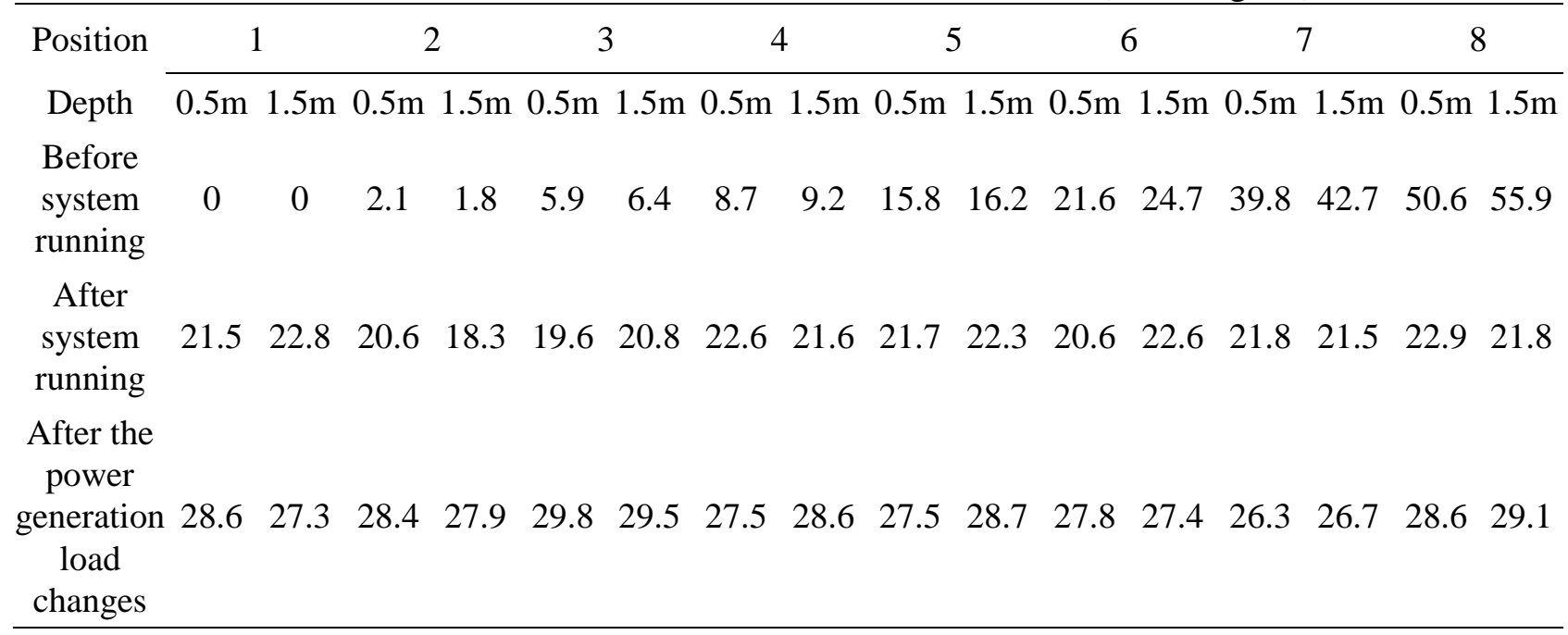

\section{Conclusion}

An innovative system for online evaluation of denitration catalyst activity and automatic adjustment of AIG spray distribution is proposed in this study. With the real-time online detection of $\mathrm{NO}_{x}$ concentration distribution and flue gas velocity distribution, an overall performance of SCR system can be calculated and analyzed.

The catalyst activity evaluation of SCR denitration is an important parameter for catalyst lifecycle management. The abnormal of catalyst activity can also be detected in time for further treatment. It is a reliable technology for emission reduction.

The automatic adjustment of AIG ammonia spray distribution could control the ammonia escape concentration at minimal level at any time. The clogging and agglomeration problems in the air preheater and dust filter could be prevented. The operation and maintenance costs can be reduced for coal-fired power plants.

With the proposed system, the catalyst activity evaluation and AIG spray adjustment can be achieved simultaneously. A better economy and environment performance could be obtained. It is a practical improvement technique for coal-fired power plants. 


\section{Acknowledgments}

This work was sponsored by the Self-Financing Project of State Grid Henan Electric Power Research Institute (Y1405).

\section{References}

[1] D. Xiangwan: Electric Power Vol. 50 (2017), p. 1

[2] F. Qianwei, Z. Yang, W. Fengji and Z. Yue: Electric Power Vol. 50 (2017), p. 157

[3] Z. Tingwen, Y. Mingyu, F. Kangli, C. Guangwen, Y. Song, L. Yang and C. Ming: Thermal Power Generation Vol. 46 (2017), p. 1

[4] X. Kaijie, W. Jing, L. Zhihua and P. Lili: Environmental Pollution \& Control Vol. 39 (2017), p. 504

[5] Z. Hongwei, Z. Zhongwei, H. Bobo and M. Hongbao: Automation \& Instrumentation Vol. 1 (2017), p. 161

[6] Z. Qingchuan, H. Weidong, H. Zhihong, D. Xinguang, D. Jian, Chinese Patent No. CN201310173825.9. (2013)

[7] S. Dekui, L. Guofu, Z. Yi, X. Rui: Chinese Patent No. CN201510514520.9. (2015) 